\title{
Blowing snow in Antarctica and its contribution to the surface mass balance
}

Franziska Gerber ${ }^{1,2}$, Varun Sharma ${ }^{1,2}$ and Michael Lehning ${ }^{1,2}$ franziska.gerber@slf.ch

${ }^{1}$ CRYOS, École Polytechnique Fédérale de Lausanne, Lausanne, Switzerland ${ }^{2}$ WSL Institute for Snow and Avalanche Research SLF, Davos, Switzerland

\section{$\mathbb{N}_{\text {ws }}$ 棪紫 EPFL}




\section{CRYOWRF: a new coupled atmosphere-snow model}

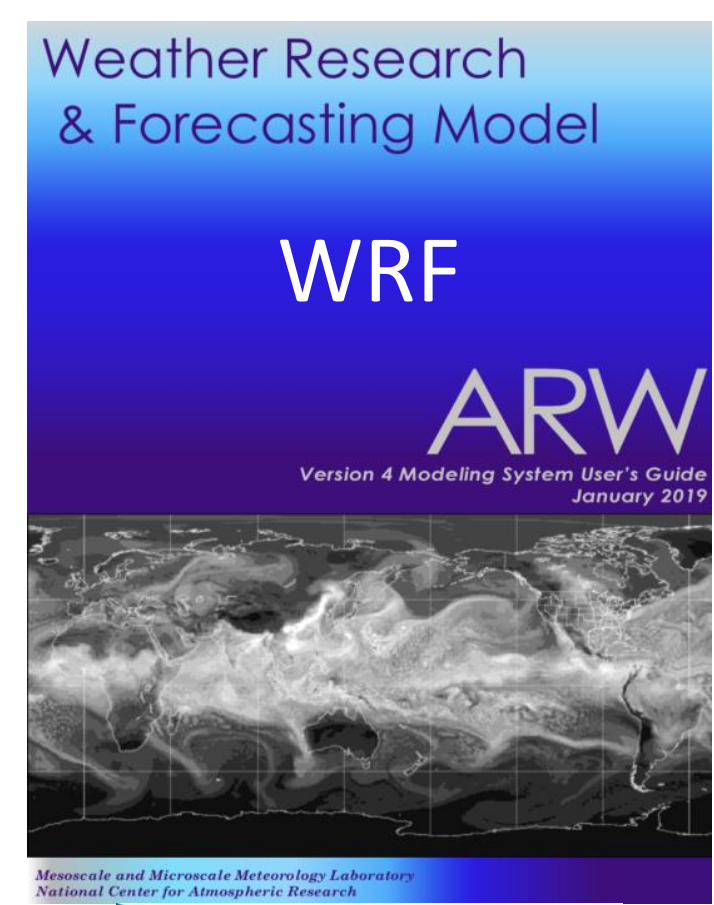

DNCAR

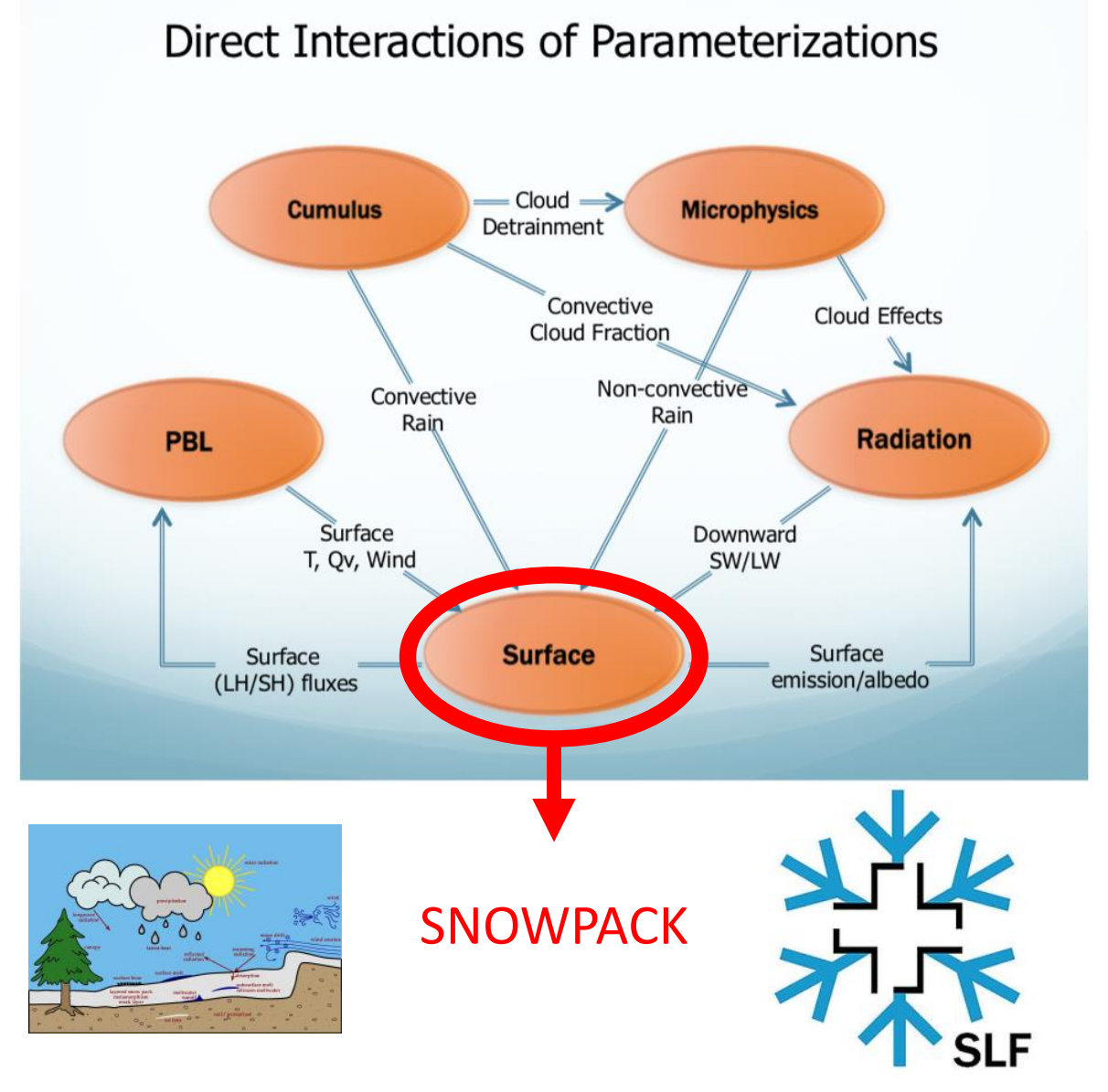

\section{CRYOWRF}

- CRYOWRF couples the atmospheric Weather Research and Forecasting model (WRF) with the snow model SNOWPACK

- Includes grain information of multiple snow layers

- Additional near-surface atmospheric layers for blowing snow

- Interaction of blowing snow and precipitation

Fully coupled non-hydrostatic model including blowing snow interaction with the atmosphere 


\section{Surface mass balance (SMB) in Antarctica}

CRYOWRF without blowing snow (annual mean)

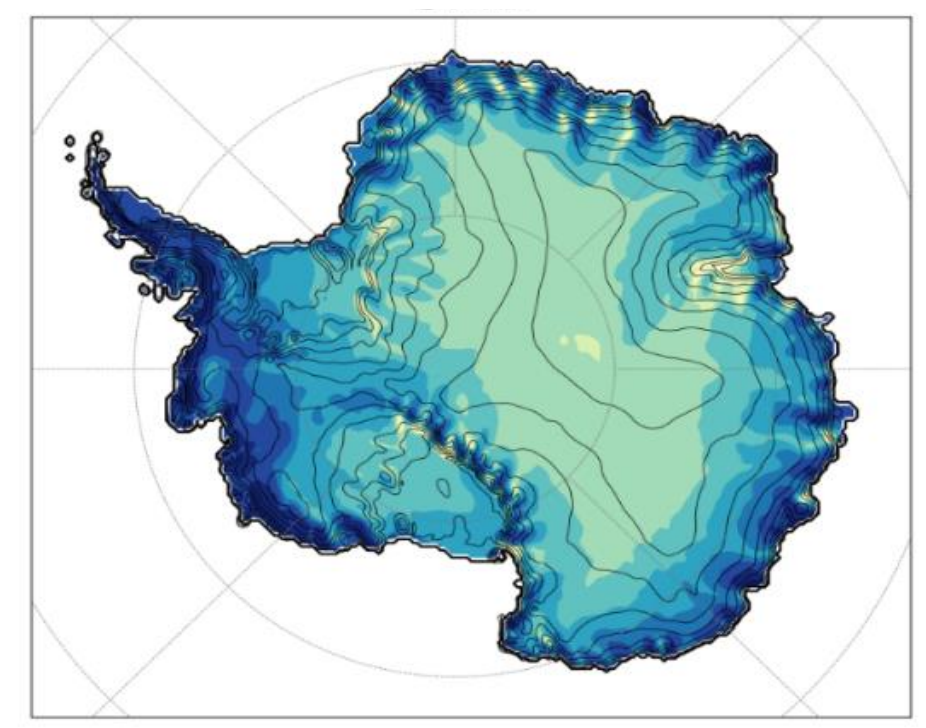

SMB = Precipitation - Sublimation

CRYOWRF period: 2011-07-01 - 2017-07-01

\section{SMB in CRYOWRF}

- without blowing snow

- 7-years simulation (1 year spinup)

- Annual mean surface mass balance for the period 2011-0701 - 2017-07-01

- High SMB in coastal regions, low SMB over continent

SMB in CRYOWRF without blowing snow in good agreement with SMB in Agosta et al., 2019
SMB in Agosta et al., 2019

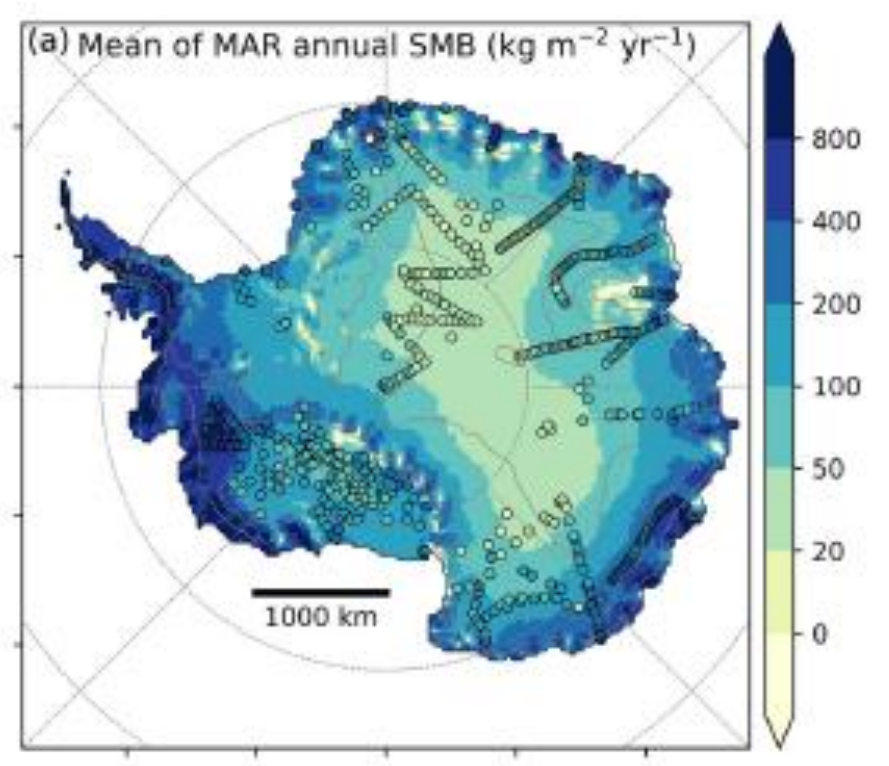




\section{Surface mass balance (SMB) in Antarctica}
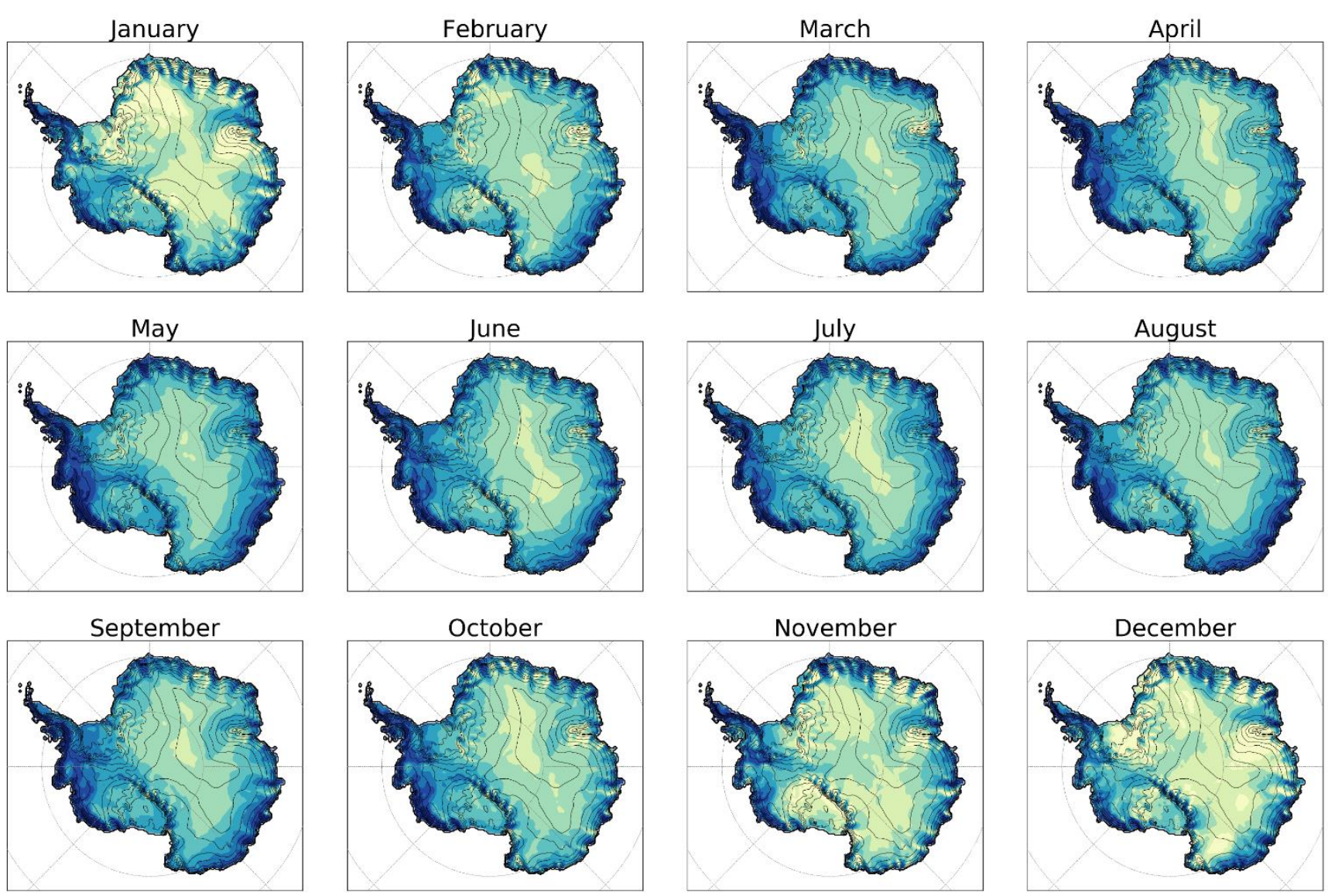

Monthly SMB in CRYOWRF

- without blowing snow

- 7-years simulation (1 year spin-up)

- Monthly mean surface mass balance for the period 2011-07-01 - 2017-07-01

- Seasonal differences

More negative SMB in summer months in agreement with warmer temperatures and higher sublimation rates (see next slide). 


\section{Surface mass balance (SMB) in Antarctica}
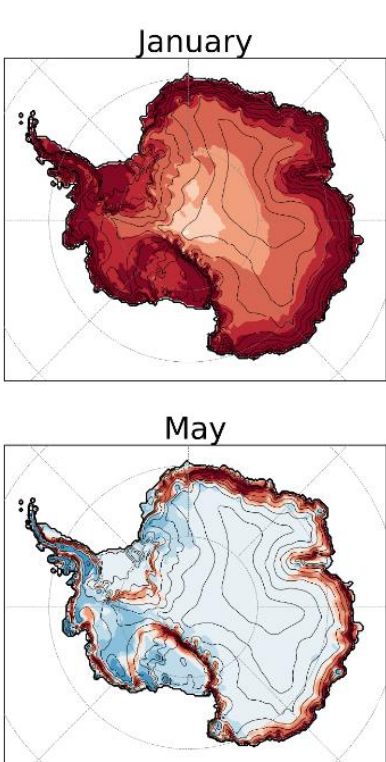

September

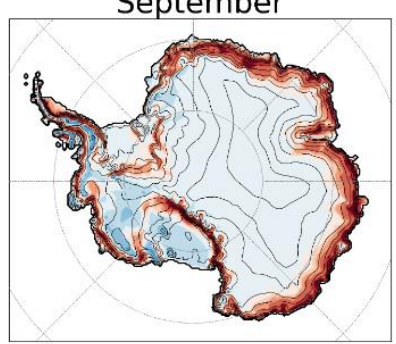

February

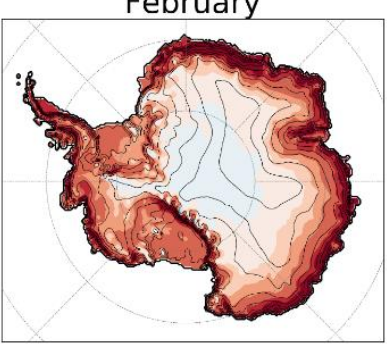

June

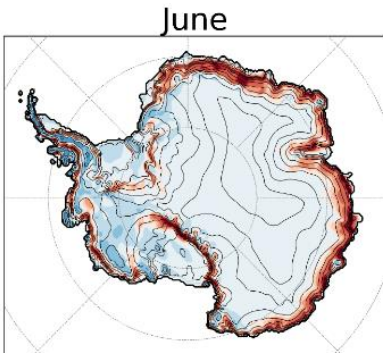

October

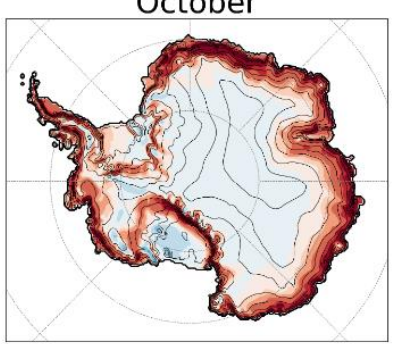

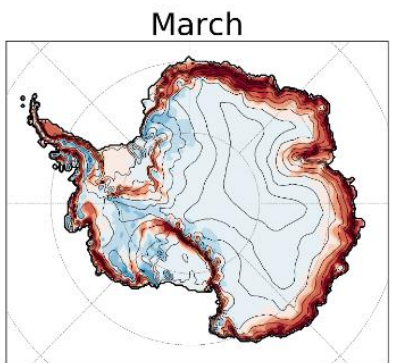

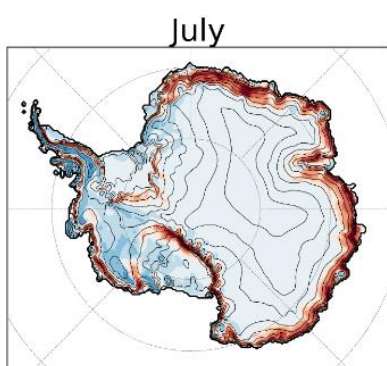

November

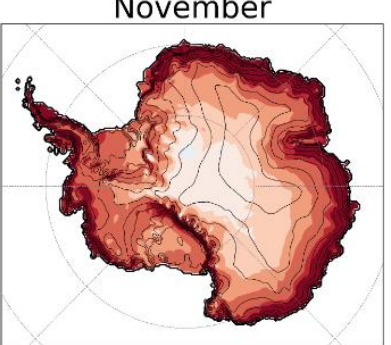

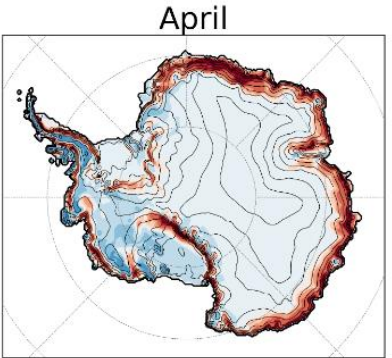

August

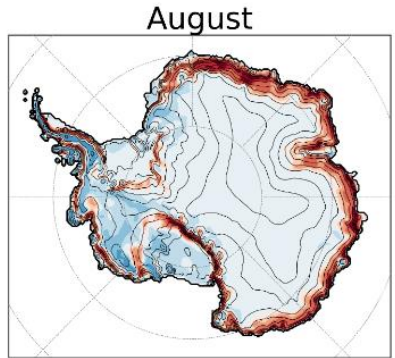

December

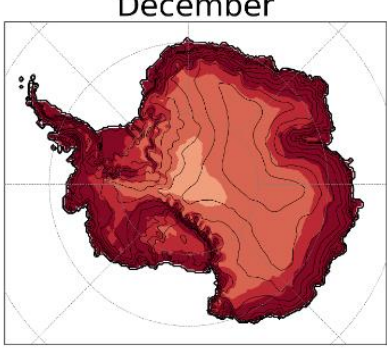

Monthly sublimation in CRYOWRF

- without blowing snow

- 7-years simulation (1 year spin-up)

- Monthly mean surface mass balance for the period 2011-07-01 - 2017-07-01

- Strong regional and seasonal differences

\section{Sublimation strongest over the coastal} regions and in summer. Deposition over the continental regions in winter. 


\section{Surface mass balance (SMB) in Antarctica}
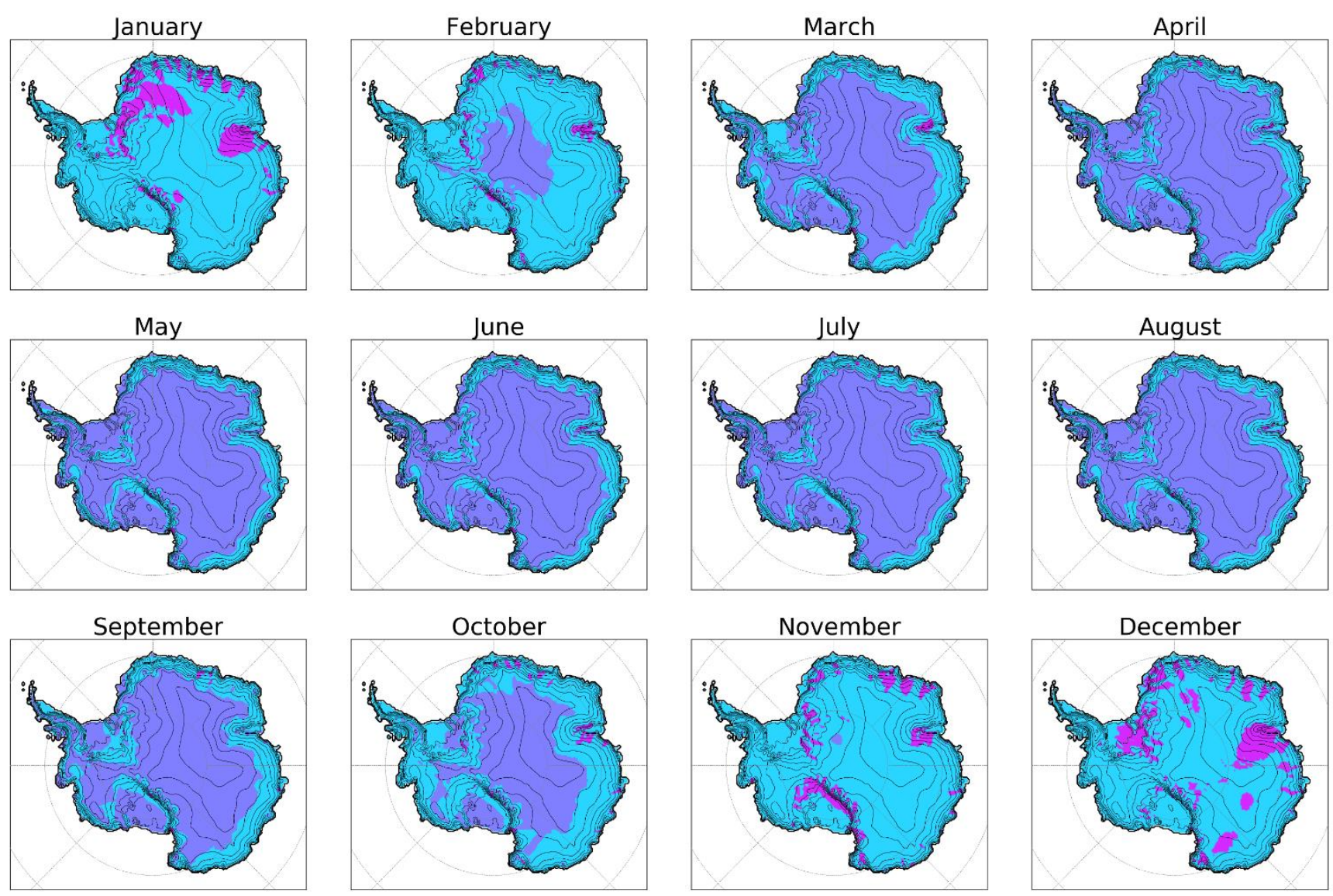

Monthly dominant regimes in CRYOWRF

- without blowing snow

- 7-years simulation (1 year spin-up)

- Monthly mean surface mass balance for the period 2011-07-01 - 2017-07-01

- 3 regimes:

- Less sublimation than precipitation

- Deposition adds to precipitation

- More sublimation than precipitation

Regions where sublimation exceeds precipiation, even in the annual mean (e.g. Amery region). 


\section{Blowing snow in Antarctica}

CRYOWRF monthly blowing snow frequencies
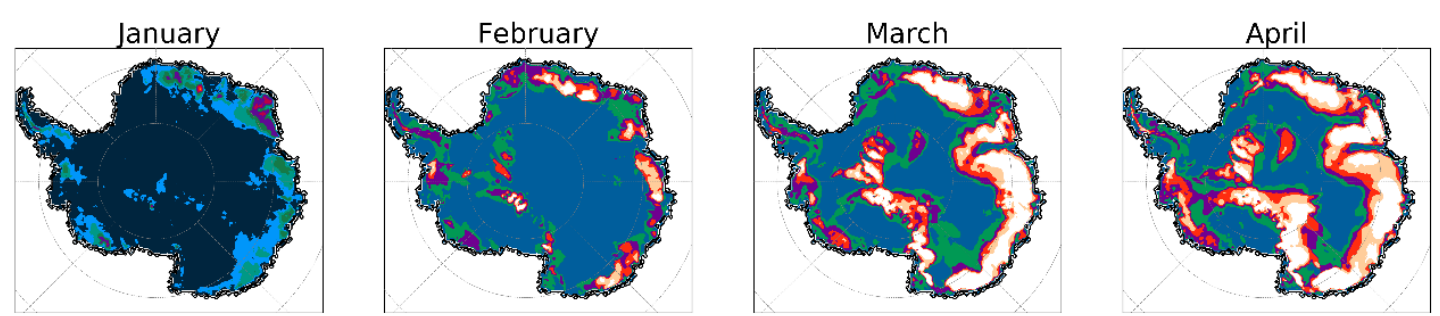

Palm et al., 2018*
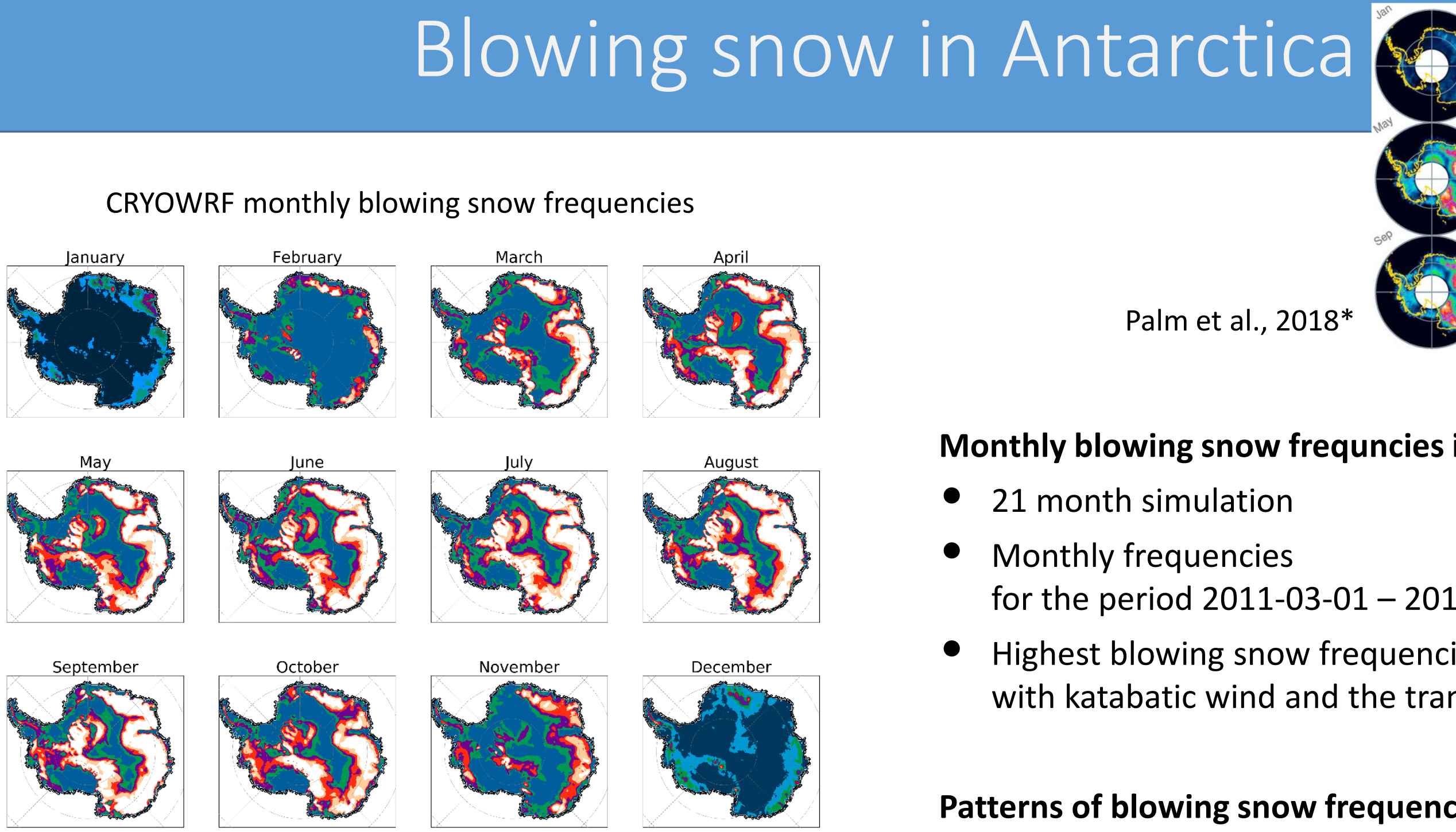
with patterns from the satellite product by Palm et al. 2018 (see next slide for zoom-in)

Monthly blowing snow frequncies in CRYOWRF

- 21 month simulation

- Monthly frequencies for the period 2011-03-01 - 2012-12-31

- Highest blowing snow frequencies in coastal regions with katabatic wind and the transantarctic mountains

Patterns of blowing snow frequency in good agreement

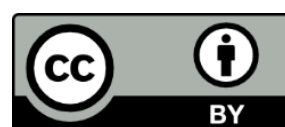




\section{Blowing snow in Antarctica}

CRYOWRF monthly blowing snow frequencies
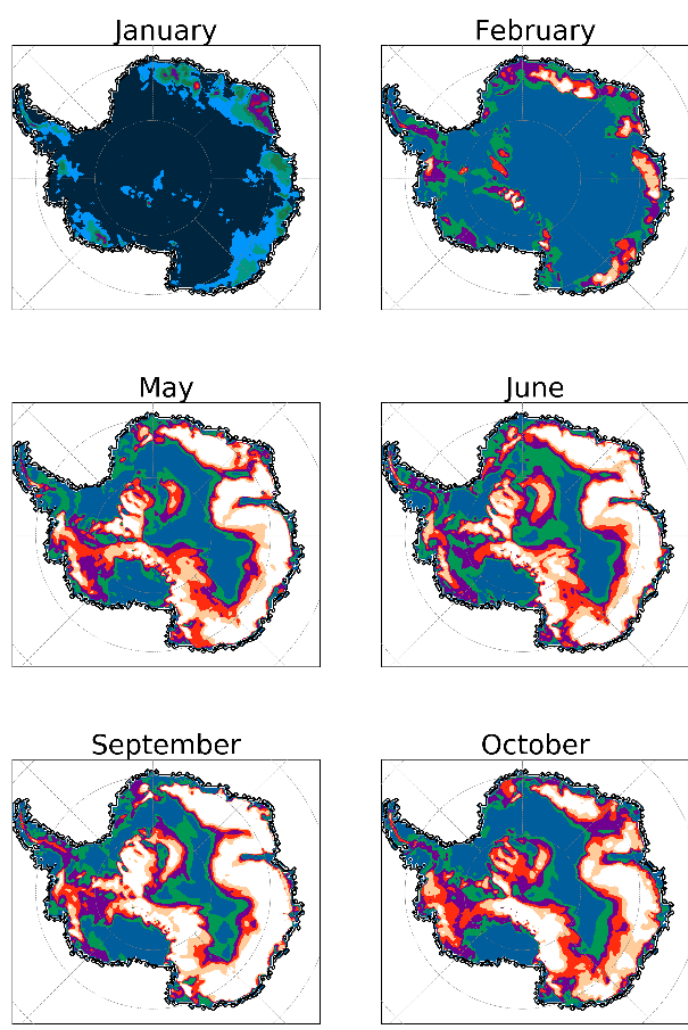
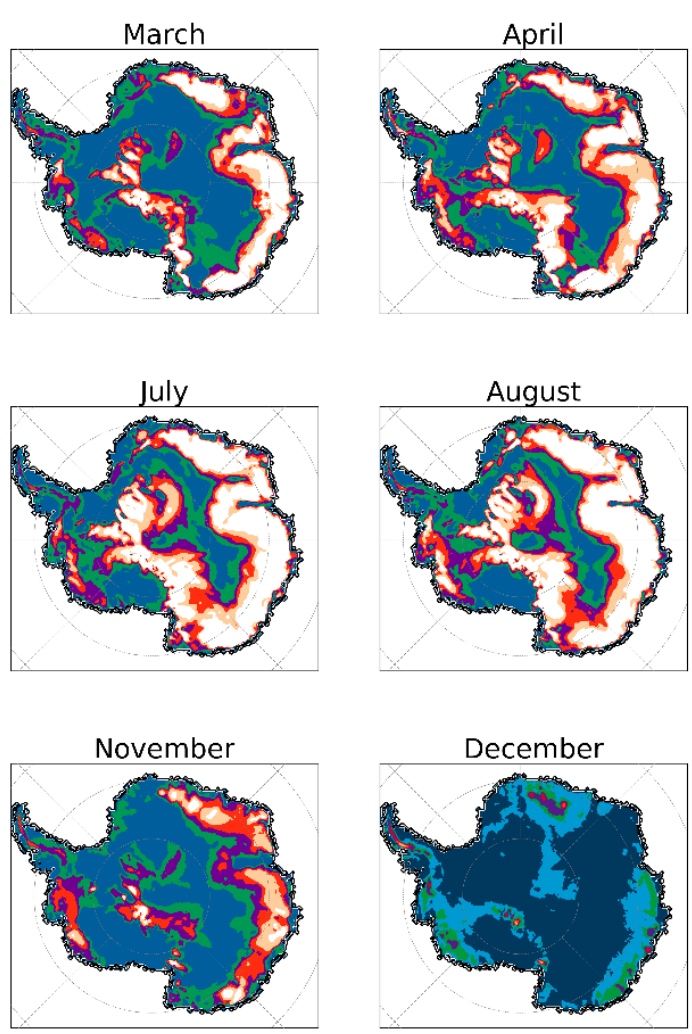

Satellite product of monthly blowing snow frequencies by Palm et al., 2018*

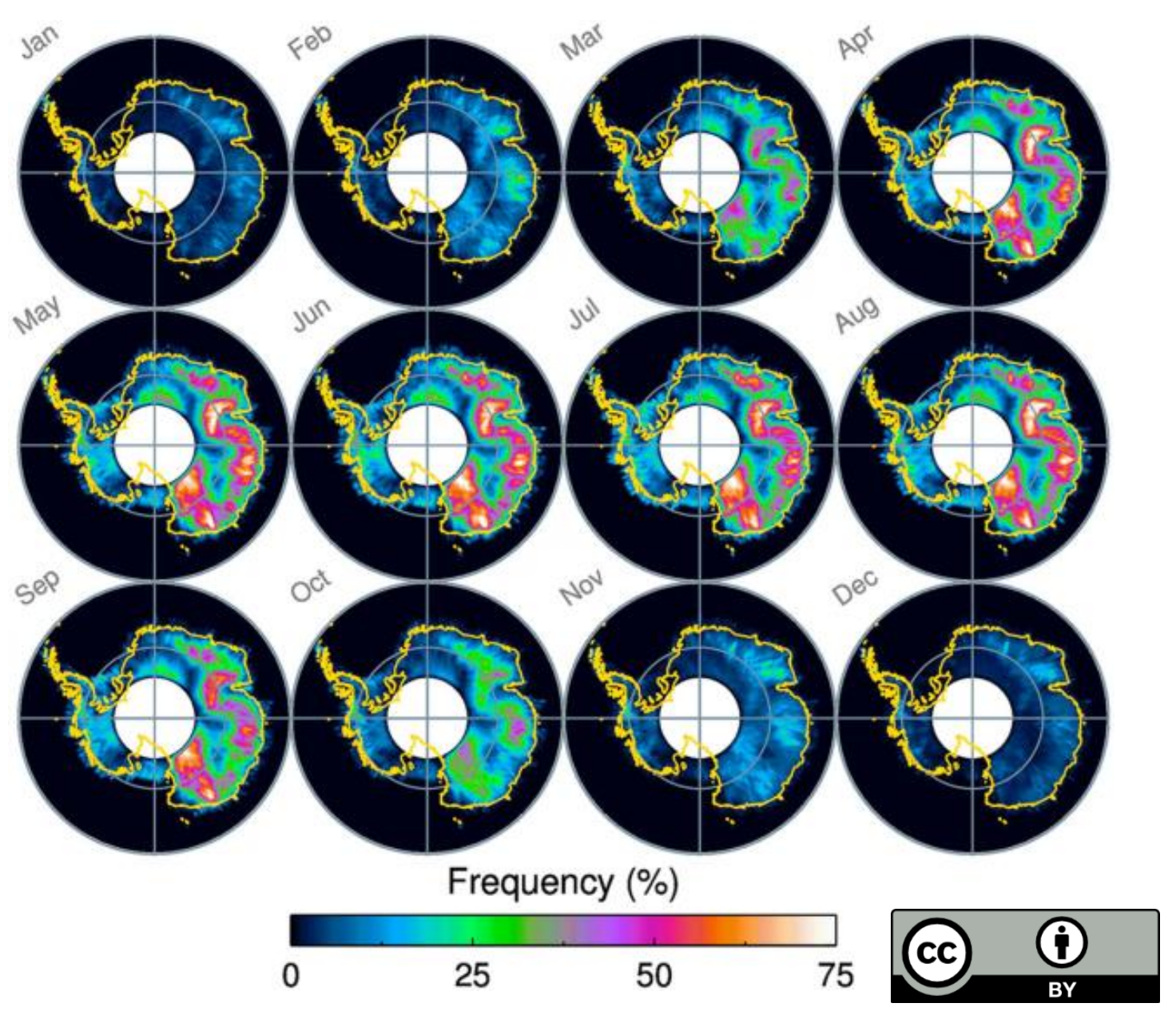




\section{Conclusion}

- Good agreement of CRYOWRF (without blowing snow) to the study by Agosta et al., 2019

- Strong regional differences of surface sublimation

- Blowing snow frequency patterns well represented compared to the satellite product by Palm et al., 2018

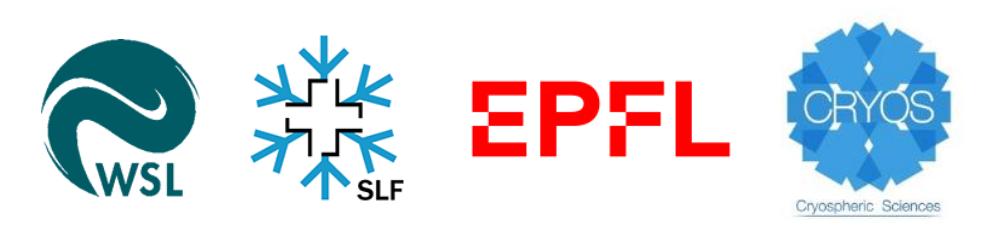




\section{References}

- Agosta, C., Amory, C., Kittel, C., Orsi, A., Favier, V., Gallée, H., van den Broeke, M. R., Lenaerts, J. T. M., van Wessem, J. M., van de Berg, W. J., Fettweis, X., 2019: Estimation of the Antarctic surface mass balance using the regional climate model MAR (1979-2015) and identification of dominant processes, The Cryosphere, 13, 281 - 296, https://doi.org/10.5194/tc-13-281-2019

- Palm, S. P., Kayetha, V. and Yang, Y., 2018: Toward a satellite-derived climatology of blowing snow over Antarctica, Journal of Geophysical Research - Atmospheres, 123, 10301 - 10313, https://doi.org/10.1029/2018JD028632

* Figure 4, reproduced with permission of the publisher under the license number 4821281402153, May 03, 2020; Published 2018. This article is a US Government work and is in the public domain in the USA.)

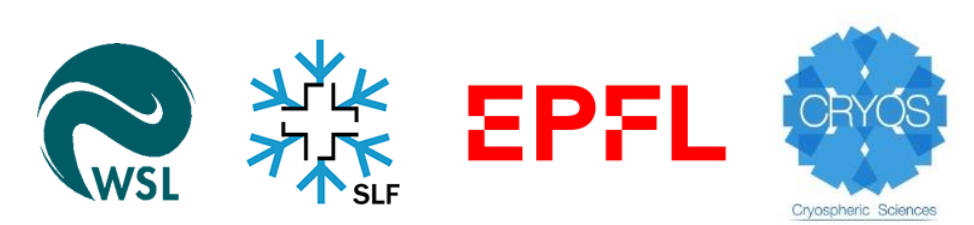

